\title{
POLICY STATEMENT: SUPPORT TO ATHLETIC EVENTS
}

\section{THE PODIATRY ASSOCIATION - PODIATRIC SPORTS MEDICINE GROUP}

\section{INTRODUCTION}

Whilst welcoming any opportunity to provide support and advice to organisers and competitors the Association is concerned that reasonable minimum standards of professional care shall be maintained. The experience of our members who have been involved with large scale events to date indicates that the level of provision of organisation and facilities for medical support is varied and inconsistent. In particular, the growing trend for mass participation marathons has provided examples of serious omissions.

It is anticipated that the provision of medical support will invariably be a multidisciplinary function. The Podiatry Association is anxious to ensure that the contribution of its own members is on a proper basis in terms of clinical effectiveness, organisation and professional ethics. The following requirements are therefore proposed as the minimum consistent with these principles.

\section{PLANNING}

Although local Podiatrists and State Registered Chiropodists may readily offer assistance a representative of this Association appointed by its Sports Medicine Committee should be invited to meet the organising committee at an early stage with a view to coordinating an appropriately sized team of professional colleagues. The Hon. Secretary of the Podiatric Sports Medicine Group should be consulted in this respect.

In a multidisciplinary situation, (podiatrists, doctors, physiotherapists, first aid organisations, etc.), the leaders of each discipline should meet to agree on a co-ordinated approach.

\section{FACILITIES}

It is accepted that there are widely varying situations and venues. The following points should be given priority:

1. Space. The team of Podiatrists require adequate space in which to examine competitors before and after the event. Where temporary accommodation is in use (e.g. tents or marquees), a separate unit or designated portion of a larger unit is needed. In the case of fixed buildings medical facilities in general should be separate from changing, administrative or public areas. In all situations consideration should be given to security and privacy.

2. Location. As close to the finish of the event as possible, facing the finish line and with the facility to channel those competitors needing attention into the medical area away from other competitors and spectators.

\section{Services. Lighting and power. \\ Heating if appropriate. \\ Water supply. \\ Waste disposal.}

Tables, benches and seats as required.

Floor covering, especially over grass or mud.

Fluid and electrolyte replacement drinks at finish and in medical area.

Refreshments for medical support personnel.

Clear signposting to the medical area with security personnel regulating entry.

A sufficient number of official badges, passes, parking permits, etc.

Ambulance access.

\section{FINANCE}

It is understood that professional services at the event are given free by members of this Association, notwithstanding the reimbursement of any reasonable expenses incurred as agreed with the event organisers. The co-ordinating podiatrist to submit an estimate and subsequent account for consumables such as strappings, dressings, sterile sharp instruments and other incidentals and an undertaking given by the organisers to meet these costs.

\section{PUBLICITY}

It is essential to notify competitors in advance of the podiatric and other medical facilities which are to be provided before, during and after the event. Also, clear instructions on how to avail themselves of those facilities.

The Podiatry Association is appreciative of any formal acknowledgement of the service provided by its members.

\section{INFORMATION AND ADVICE}

The Podiatric Sports Medicine Group has available a selection of pre-race advice sheets aimed particularly at the novice runner which may be duplicated and distributed with other pre-race correspondence. In addition, the committee will be pleased to nominate experienced speakers to participate in any educational programmes or forums associated with the event.

\section{DATA ACQUISITION}

As part of its research function the Podiatric Sports 
Medicine Group accumulates information and statistics relating to sports events and injury. In this context the co-ordinating podiatrist may request facilities to interview and examine competitors and for access to official statistics and results.

FURTHER DETAILS from Mrs. H. Swindley, MChS, SRCh, 60 Briar Drive, BUCKLEY, Clwyd.

Title:

\section{BOOK REVIEW}

Author: Noel Roydhouse, ChM(Otago), FRCS(Eng), FRACS

Publisher: $\quad$ N. Roydhouse, 118 Remuera Road, Auckland 5, New Zealand, 1981

One's confidence in this booklet is shaken on the title page by Reference to a Foreword which was not present in the reviewer's copy. However the important points in this booklet are clearly made and discussed. The use of case histories/ anecdotes gives a spice to the lively style, which involves provocative comment, e.g. "Collection of wax in the ear is a self-inflicted condition".

As it is privately published, it lacks, inevitably, minor editing refinements such as avoiding the need to search for Figures quoted in the text but placed in other sections by giving the page number on which it appears, or the desirability of using a well annotated line diagram beside a photograph or X-ray to make the point of the illustration clear to the non-specialist.

Despite these imperfections this is a very useful publication for all doctors involved with individuals who wish to deviate from atmospheric pressures - and a useful refresher for the others.

D. E. Mackay

Title:

\section{JOURNAL REVIEW}

Editor: JOURNAL OF SPORTS SCIENCES. VoI. 1 No. 11983

Publishers:

Thomas Reilly

E. \& F. N. Spon, London, on behalf of the Society of Sports Sciences. 3 times a year

Price: UK £35, overseas $£ 45$. 92 pages.

This new journal, published on behalf of the Society of Sports Sciences, a relatively recent British society founded in 1977 is produced in the UK, but obviously has the American market much in mind. There are no advertisements in this first issue, though a UK agency has been appointed for the receipt of advertisements. The journal is very well produced, set in letterpress on a good quality paper. Each of the four main articles start on new pages, there are five pages of book reviews, and thirteen pages of abstracts forming the Proceedings of the April 1983 Conference on the Endurance Athlete held in Birmingham. Five pages are devoted to details of forthcoming events.

The four main articles reflect our own difficulty in getting good quality papers from the UK. H. Hatze (Vienna) describes his computerised analysis of several sports, and what is of great interest is his account of the analysis revealing limited hip extension in a long jumper, which, when corrected increased his maximum performance from $6.96 \mathrm{~m}$ to $7.12 \mathrm{~m}$, an improvement of some $6 \frac{1}{2}$ inches. Two articles are from the USA, Carl Foster of the Mount Sinai Medical Centre confirms that maximum oxygen uptake is a good indicator of future running potential, that the quality of training is more important than the quantity, and that more accurate methods of evaluating training are needed. D. Patricia Gray and Edwin Dale (Obstetrics and Gynaecology Dept., Atlanta) discuss the role of stress and hormonal factors upon the menstrual disturbances in athletes, and there is a thirty page article by Niels Secher, of the August Krogh Institute, Copenhagen, on the physiology of rowing, based upon oxygen uptake, heart rate and muscular strength. Their 106 references alone make the article of value, as most of the major articles on exercise physiology are included.

I would regard this journal as an essential inclusion in any laboratory involved in exercise physiology. It is not designed as a rival to any existing publication, its Editorial Board includes Clyde Williams, recently. appointed Associate Editor to the British Journal of Sports Medicine, eight members of its Advisory Board are members of BASM, two of whom, David Brodie and Frank Sanderson, are newly appointed to our Executive Committee, so there should be helpful liaison between our publications.

H. E. Robson 